January 2005 - NREL/TP-620-37102

\title{
R\&D Advancement, Technology Diffusion, and Impact on Evaluation of Public R\&D
}

\author{
M.C. Moore, D.J. Arent, and D. Norland
}

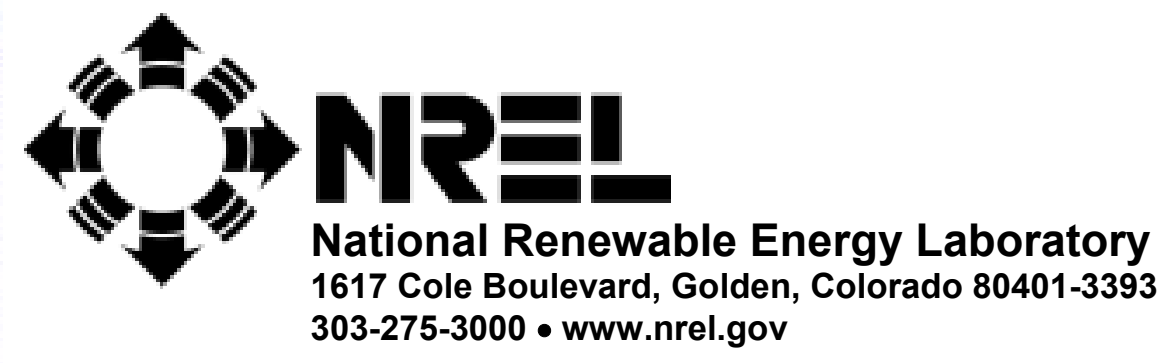

Operated for the U.S. Department of Energy Office of Energy Efficiency and Renewable Energy by Midwest Research Institute $\bullet$ Battelle 


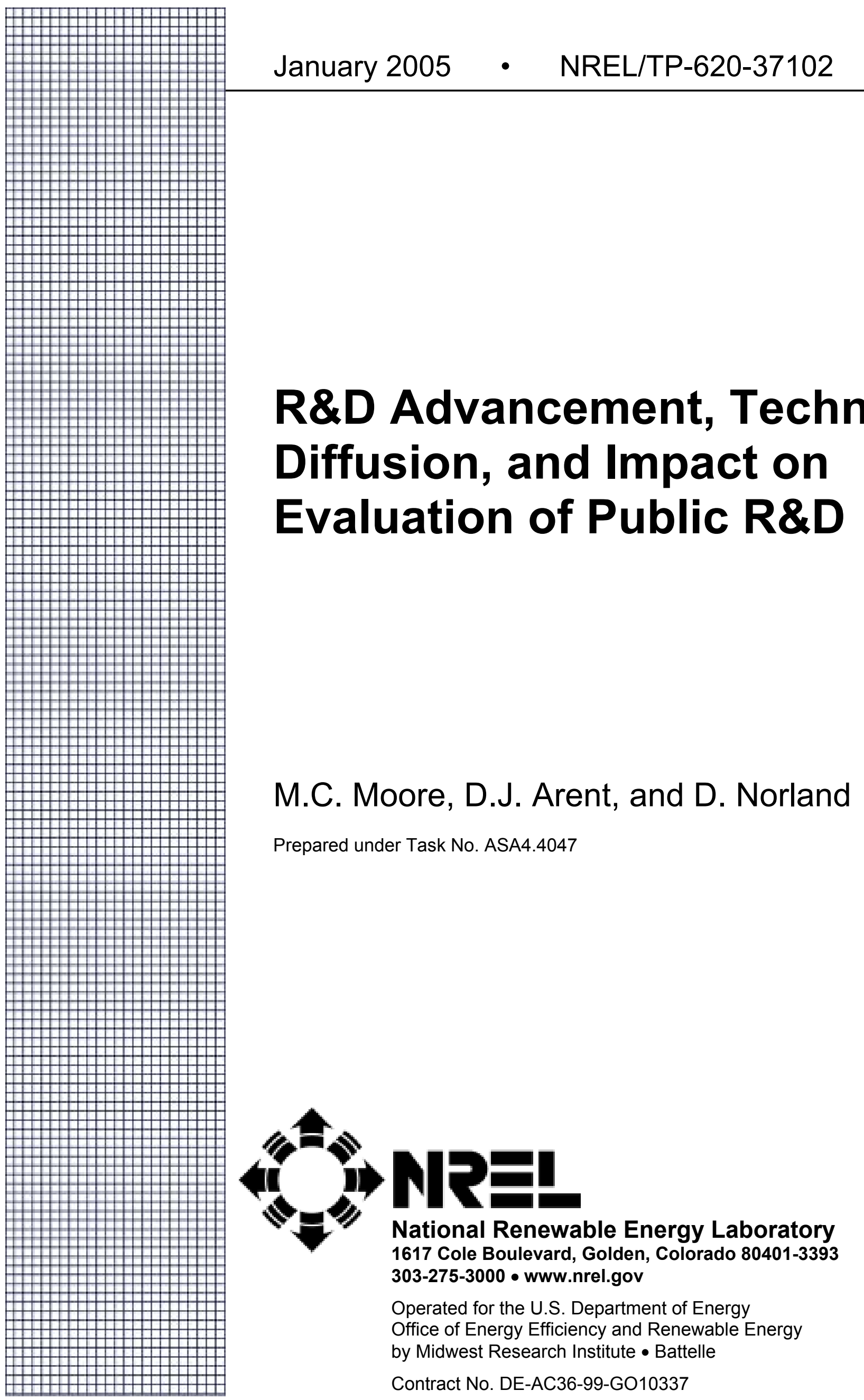




\section{NOTICE}

This report was prepared as an account of work sponsored by an agency of the United States government. Neither the United States government nor any agency thereof, nor any of their employees, makes any warranty, express or implied, or assumes any legal liability or responsibility for the accuracy, completeness, or usefulness of any information, apparatus, product, or process disclosed, or represents that its use would not infringe privately owned rights. Reference herein to any specific commercial product, process, or service by trade name, trademark, manufacturer, or otherwise does not necessarily constitute or imply its endorsement, recommendation, or favoring by the United States government or any agency thereof. The views and opinions of authors expressed herein do not necessarily state or reflect those of the United States government or any agency thereof.

Available electronically at http://www.osti.gov/bridge

Available for a processing fee to U.S. Department of Energy and its contractors, in paper, from:

U.S. Department of Energy

Office of Scientific and Technical Information

P.O. Box 62

Oak Ridge, TN 37831-0062

phone: 865.576.8401

fax: 865.576.5728

email: mailto:reports@adonis.osti.gov

Available for sale to the public, in paper, from:

U.S. Department of Commerce

National Technical Information Service

5285 Port Royal Road

Springfield, VA 22161

phone: 800.553 .6847

fax: 703.605.6900

email: orders@ntis.fedworld.gov

online ordering: http://www.ntis.gov/ordering.htm 


\section{Abstract}

In a 2001 report titled Research at DOE: Was It Worth It?, a National Research Council (NRC) committee defined a set of simplifying rules to estimate the net economic benefits from technologies supported by the Department of Energy (DOE). We evaluate the efficacy of the $\mathrm{NRC}$ rules compared to published literature on acceleration of technology introduction into markets, technology diffusion, and infrastructure change. We also offer considerations for revisions of the rules that call for the use of technology and sector-specific data, advanced forecasting techniques, and sensitivity analysis to test the robustness of the methodology. 


\section{Introduction}

Public-sector investments are made to generate public benefits such as safety, security, and protection of natural resources. Measuring the benefits of public-funded research and development $(\mathrm{R} \& \mathrm{D})$ has garnered considerable attention from economists, program managers, and policy makers. While there is extensive evidence in the literature stating that publicly funded R\&D leads to considerable economic benefits, there continues to be little agreement on the methodologies for assessing the benefits. ${ }^{1,2}$ Economic methods include macroeconomic production functions, investment analysis, and consumer and producer surplus techniques. Output methods include bibliometric, patent count, converging partial indicators, and science indicators approaches. ${ }^{3}$ Methods for assessing other benefits - e.g., the benefits associated with providing options in the event of anticipated crises — are only now receiving initial attention. ${ }^{4}$

More recently, estimates of the economic rates of return ranging from $20 \%-67 \%$ to publicly funded R\&D have been published for specific projects. ${ }^{5}$ These studies employed traditional economic methodologies such as production functions, investment analysis, and consumer and producer surplus techniques. Investment-analysis measures include net present value (NPV) or return on investment (ROI). These traditional corporate measures, while widely used for measuring public-sector benefits, are strongly affected by the discount rate and time-of-study assumptions. A significant body of literature addresses the estimation of appropriate discount rates for publicly funded $R \& D$, but has little consensus on rates for the measurement of broad societal benefits such as security and protection of natural resources. ${ }^{6}$ However, there is general consensus that policy makers should be more patient than private citizens or corporations.

The issue of appropriate time periods for evaluation of public R\&D investments is important for accountability and in estimating needed future investments and research agendas. As such, time frames for conducting economic analysis are beginning to receive attention. For example, the time frame for adoption of new fundamental technology in a specific sector may be long relative to products that represent an incremental advance or improvement on existing technologies or products, thus requiring different time periods for assessment of economic benefits. ${ }^{7}$ Tassey, in his 2003 report, states " the timing of an economic impact study therefore presents a difficult

\footnotetext{
${ }^{1}$ L. Georghiou and D. Roesner; "Evaluating Technology Programs: Tools and Methods,” Research Policy 29:657$678,2000$.

${ }^{2}$ The ability to capture all related returns to a given invention. See, for example, "Interaction Between The Public Sector And Technological Innovation: Government Policy Towards Research And Development," United Nations, 1999.

${ }^{3}$ See, for example, "Research Funding as an investment: Can we measure the returns," technical memorandum, Office of Technology Assessment, 1986.

${ }^{4}$ N. Vornortas and M. Lakey; "Real Options for Public Sector R\&D Investments," Learning from Science and Technology Policy Evaluation: Experiences from the United States and Europe, Stephan Kuhlmann and Philip Shapira (eds.), Edward Elgar, Cheltenham UK and Northampton, U.S.A, 2003.

5 A. Salter and B. Martin; "The economic benefits of basic research: a critical review," Research Policy 30 (1): $509-$ 532, 2001.

${ }^{6}$ See, for example, A. Caplin and J. Leahy; "The Social Discount Rate," New York University working paper, 2004.

${ }^{7}$ A. Grubler, N. Nakicenovic, D. Victor; "Dynamics of energy technologies and global change," Energy Policy 27: 247-280; 1999; A Grubler, "Time for a Change: On the Patterns of Diffusion and Innovation," in Technological Trajectories and The Human Environment, National Academies Press, 1997.

${ }^{8}$ G. Tassey; "Methods for Assessing the Economic Impacts of Government R\&D," National Institute of Standards and Technology, 2003.
} 
problem. The significant time required for diffusion and impact of major elements of an industrial technology...must be traded off against the perishable nature of impact data." Further, Tassey states "the ideal time to conduct an economic impact study seems to be about three to ten years after significant marketplace impact has commenced." More recently, the NRC defined a set of time-frame rules that they utilized in estimating the net economic benefits of publicly funded R\&D, suggesting that conservative estimates would be obtained by employing simplified rules. $^{9}$

\section{NRC Framework for Evaluating Costs and Benefits of Public-Sector Research}

Public and private entities use predictably different standards for measures of success. For a private-sector firm, common metrics for measuring the impact of investments include product sales, cost of production, and protection of market share. R\&D programs are measured against their ability to expand or refine that market or to find new market niches that generate investor interest and company commitment of competitive capital resources. In contrast, the public sector-responsible for anticipating and reacting to national needs - increases public welfare by investing in technologies, intellectual capital, or new techniques of manufacturing. Because the benefits of public investment may span multiple sectors, accurately measuring the net economic benefit may call for the use of a variety of evaluation tools. ${ }^{1-4,6,10}$ As pointed out by Tassey, ${ }^{6}$ selection of specific metrics for public-sector projects depends on several factors, including the type of R\&D targeted by the project being studied and the objectives of the broader research program of which the project is a part (which may include industry structure and growth objectives). Specifically, metric selection should be determined by the following criteria: (i) simple and computable, (ii) persuasive, (iii) consistent and complementary, (iv) technology and industry independent, and (v) usefulness of feedback.

In its 2001 study, the NRC established an evaluation framework for evaluating public-sector research. ${ }^{2}$ The matrix below, which summarizes the framework, was designed to capture (1) benefits that the private economy cannot reap from DOE research and (2) realized benefits in cases when a technology either does not enter the marketplace or does not enter to a significant degree. We directly extract language from the NRC study to avoid any possible misinterpretation.

\begin{tabular}{|l||c|c|c|}
\hline & $\begin{array}{c}\text { Realized Benefits and } \\
\text { Costs }\end{array}$ & $\begin{array}{c}\text { Options Benefits and } \\
\text { Costs }\end{array}$ & $\begin{array}{c}\text { Knowledge Benefits and } \\
\text { Costs }\end{array}$ \\
\hline \hline Economic benefits and costs & & & \\
\hline $\begin{array}{l}\text { Environmental benefits and } \\
\text { costs }\end{array}$ & & & \\
\hline Security benefits and costs & & & \\
\hline
\end{tabular}

The rationale and methodologies for applying the framework, as stated by the NRC, are:

\footnotetext{
${ }^{9}$ Energy Research at DOE: Was It Worth It?, National Research Council, 2001.

${ }^{10}$ G.S. McMillan and R. D. Hamilton III; "The Impact of Publicly Funded Basic Research: An Integrative Extension of Martin and Salter," IEEE Transactions on Eng. Mgmt 50(2), 184-191, 2003.
} 
Based on these stated objectives, the committee adopted the three generic classes of benefits (and related costs) for the energy R\&D programs: "economic," "environmental," and "security" benefits. The entry in each cell of the matrix is a measure of the economic, environmental, or security net benefit further characterized according to the column classification schemes, discussed below. Economic costs, or undesirable consequences, are quantified as negative components of net benefits, and economic benefits, or desirable consequences, as positive components. Ideally, the entries in the cells would be quantitative measures of each category of net benefits; in some cases, however, only qualitative descriptors are possible.

We focus on the economic-benefits evaluation. Specifically, the NRC committee has adopted a set of assumptions for evaluating net realized economic benefits. According to the report, the methodology is as stated below:

The estimate of economic benefits resulting from an R\&D initiative is intended to measure the net economic gain captured by the economy. The impact of a new technology is measured by comparing it with the next best alternative that was available when the technology was introduced or that would have been available absent the DOE efforts. Benefits are intended to be net of all economic costs of achieving the benefits, not just the cost to the direct participants in the R\&D initiative. Benefits and costs are to be calculated on the basis of the life cycle of investments. Dollar amounts are all expressed in constant 1999 dollars. The committee did not discount benefits, costs, or governmental expenditures but added together benefits from different years, adjusted only for inflation.

Neither macroeconomic stimulation of the national economy or the creation of jobs is to be considered a benefit of an R\&D initiative. In today's national economic circumstances, such impacts are more likely to be transfers rather than net increases at the national level. In any case, the investment of similar amounts of funds elsewhere in the economy would also have impacts. To attribute net macroeconomic benefits to a particular R\&D initiative, therefore, would be highly speculative and should not be done.

Unintended improvements in economic activities that are unrelated to the objectives of the R\&D initiative usually should not be counted as benefits in evaluating the success of the R\&D. Such serendipitous results may offset the costs to the public of the initiative, but they are a random consequence of investment. Ancillary benefits might have resulted from investing the funds elsewhere. Judgment must be applied in specific cases to determine if the results are relevant to the objectives of the initiative.

Further, the NRC committee stated their approach to calculating realized economic benefits as ${ }^{11}$ :

In computing realized economic benefits, the net lifecycle effects of a completed technology are considered. However, the decreases in damages associated with reduced releases of materials as a result of the new installations may last for much longer times. Benefits are included for the entire time of this decreased damage.

Realized economic benefits should include the results of the life-cycle operation of all capital stock utilizing the technology that has been installed through the year 2000 and that is projected to be installed through 2005 (the 2005 rule). A new technology may well be adopted for new installations beyond a 5-year horizon, but for technologies that provide significant economic benefits that can be captured by private sector investments, it is reasonable to assume that at some point a comparable improvement would have been introduced in the absence of the DOE R\&D initiative. Adopting a 5-year limit (the 5-year rule) on future installations but allowing the full useful life of the installations to be considered provides a reasonable but conservative estimate of the contribution of the technology without introducing speculative projections of its longer-range impact. The committee's calculations also assume that the DOE R\&D or demonstration program advanced the introduction of new technology into the market by 5 years.

To summarize, the evaluation for net realized economic benefits is characterized by changes in the valuations based on market prices, relative to the next-best feasible alternative, subject to a

${ }^{11}$ Energy Research at DOE: Was It Worth It?, National Research Council, 2001, p 17. 
set of simplifying rules: "the 2005 rule" and "the 5-year rule." The net economic benefits are estimated using life-cycle costs or benefits, including the life-cycle costs or benefits over the entire future life of all installations. Methodologically, the NRC committee adopted procedures in which net benefits on a per-installation basis were either estimated and multiplied by the estimated number of new installations; or alternatively, summed estimated economic benefits over installations, if they were of substantially different scales. All estimates were further subject to a set of simplifying assumptions. As stated by the NRC, those assumptions include:

- No estimation of cross-sector or macroeconomic benefits

- Use of $0 \%$ discount rate (inflation adjustment only)

- Advancement of a technology into the market by five years as a result of DOE investment

- Inclusion of benefits from technology introduced into the market within five years of the date of the study

We review the impact of the assumptions of discount rate, advancement of a technology into the market, and inclusion of benefits limited to technology introduced within five years (the 5-year rule). We leave discussion of the cross-sector and macroeconomic benefits, as well as discussion of assumptions for evaluation of options and knowledge benefits, to a future paper.

\section{A. Discount rates}

Public research and private research differ based not only on their source of funds, but also by expected returns. For instance, in the private sector, research is targeted to produce a return that pays back the R\&D investment through increased sales and profit. Shareholders demand overall returns that match the expectation of the company performance; and if return expectations are not met, shareholders will abandon their interest, lowering access to capital and forcing the company to gamble on achieving a breakthrough or to retrench and focus on core competency. This relationship is uniquely described in the context of the expected ROI for the company in question. The minimum expected return on investment, expressed as the discount rate, accounts for the time value of money. For private firms, discount rates are determined by the weighted average cost of capital. Corporate discount rates are unique based on the fact that in a competitive marketplace (where capital is very mobile), the cost of capital and expected returns on investment are sector and corporation specific. In general, private-sector investments require relatively high rates of returns (i.e. $20 \%$ to $25 \%$ ) over relatively short periods of time (i.e. twofive years). There is generally little interest in investing in long-range technologies or processes without assurance that market dominance can be obtained and preserved (or protected). Good examples include patents in medicines or guaranteed contract arrangements such as those available with the military.

To highlight the role of discount rate, we offer an example of applying different discount rates (below) and demonstrate that the application of different discount rates significantly impacts the measure of economic benefits when applied with an NPV calculation.

Figure 1 shows results from a simplified model of net economic benefits as a function of discount rate, demonstrating the impact of this variable on outcomes. The model calculates NPV 
using average innovation and imitation values for the Bass diffusion model, ${ }^{12}$ correlating to approximately 20-year diffusion to full market penetration and assuming a 40:60 industry cost share of R\&D. In comparison to the OMB specified discount rate of $7 \%$, discount rates of $15 \%$ and $20 \%$ reduce the NPV estimate by $47 \%$ and $63 \%$, respectively.

Impact of Discount Rate on NPV

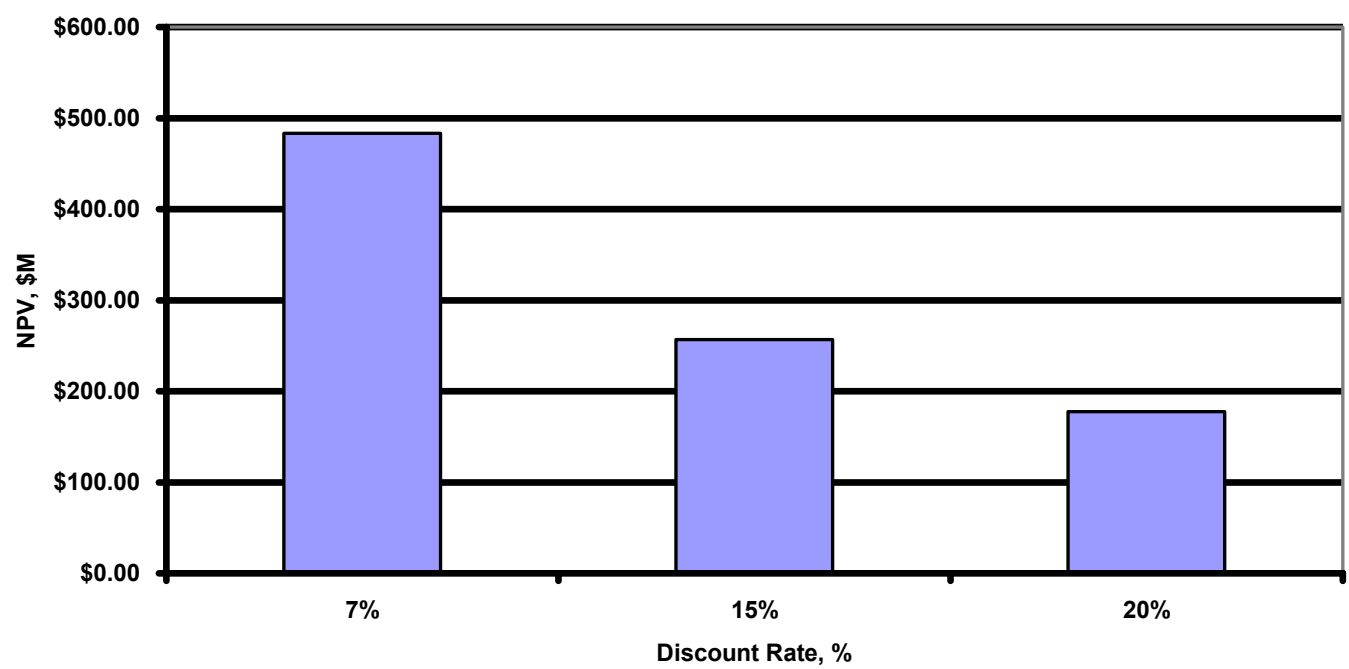

Figure 1. Impact of product advancement and discount rate on net present value for a set of cases in which average innovation and imitation values for the Bass diffusion model, corresponding to a 20-year time to maximum market penetration, are utilized and assuming a 40:60 industry cost share of R\&D.

Other studies have provided methodologies for calculating the social return on investment in contrast to applying a discount rate or set of rates to NPV methodologies. For example, a recent review by Scott et al reports rates of return to public R\&D ranging from $20 \%$ to $67 \%$ across a broad range of technologies and time frames. ${ }^{13}$ More recent microeconomic analysis of National Institute of Standards and Technology (NIST) Advanced Technology Program economic benefits, as published by Tassey, indicate social rates of return ranging from $30 \%$ (manufacturing standards) to $1,000 \%$ (standard reference materials for sulfur in fossil fuels). ${ }^{8}$

The application of discount rates to public-sector analysis may be appropriate, but is complicated by the difficulty of choosing a discount rate that reflects the responsibilities of the public sector. While financial markets lead to private discount rates, choosing a discount rate consistent with responsible government deficits, environmental protection, natural resource stewardship, and intergenerational welfare is extremely difficult.

Utilizing NPV calculations as an evaluative tool for realized economic benefits, positive discount rates reduce the net benefits that accrue in future years while more heavily weighing the costs of near-term investments in research. As a result, expensive, long-term R\&D would likely have a negative NPV. Each benefit stream (economic, environmental, or security) may be separately

${ }^{12}$ F.M. Bass; "A New Product Growth Model for Consumer Durables," Management 15, 215-227, 1969.

${ }^{13}$ A. Scott. G. Steyn, A. Geuna, S. Brusoni, E. Steinmueller; "The Economic Returns to Basic Research and the Benefits of University-Industry Relationships," Report for the Office of Science and Technology, U.K., 2001. 
calculated and discounted if an agreed upon set of metrics and discount rates were available. In the absence of such a set of metrics, the NRC study specifically chose to not discount costs and benefits; separated economic, environmental, and security benefits; and allowed for qualitative assessment when necessary.

In addition to NPV and ROI analyses, the literature includes analyses of public research using production function modeling. Estimates of the discount rate for R\&D capital stock (e.g. knowledge) as used in production function analysis are low or even zero, ${ }^{14}$ with one group arguing for a rate up to $10 \% .{ }^{15}$ However, many of the public benefits associated with fundamental R\&D are commonly ignored in evaluating net economic benefits with microeconomic tools - such as those used by the NRC committee - due to the added complexity, and thus analyses tend to understate the measure of public benefits. Vonortas and Lackey have recently argued that a number of methodological improvements are available to "greatly enhance formal assessments of strategic, long term R\&D projects". ${ }^{16}$ We leave a description of these methodologies for future work.

\section{B. Time frame for measuring returns on investment}

As stated above, the NRC committee made simplifying time-frame assumptions for the microeconomic evaluation methodology they employed:

1. The DOE R\&D or demonstration program advanced the introduction of new technology into the market by five years.

2. Realized economic benefits should include the results of the life-cycle operation of all capital stock using the technology that has been installed through the year 2000 and that is projected to be installed through 2005 (the 2005 rule).

We evaluate the efficacy of these assumptions through assessment of peer-reviewed findings.

\section{Advancement of technology introduction by $R \& D$}

First, we summarize the findings from the literature that have analyzed the impact of R\&D investment on product introduction. Here, studies have approached the question of how long it takes a technology to be introduced into the market from a number of perspectives. First, research by Mansfield ${ }^{17}$ on the impact of academic research on technology introduction found that average lag time between the most recent published academic research finding and first commercial introduction over seven industries was 7 years. His findings are consistent with those

\footnotetext{
${ }^{14}$ See, for example, C.I. Jones and J.C. Williams; "Measuring the Social Return to R\&D," Quarterly Journal of Economics, 113, 1119-1125, 1998.

${ }^{15}$ I.M. Nadiri and I. Purcha; "Estimation of Depreciation Rate of Physical and R\&D Capital in the U.S. Total Manufacturing Sector," Economic Inquiry XXXIV(1), 43-46, 1996.

${ }^{16}$ N. S. Vonortas and M. Lackey; "Real Options for Public Sector R\&D Investments" in Learning from Science and Technology Policy Evaluation: Experiences from the United States and Europe; S. Kuhlmann and P. Shipira (eds), 2003.

${ }^{17}$ E. Mansfield; "Academic research and industrial innovation," Research Policy (20) 1-12, 1991; and E. Mansfield, "Academic research and industrial innovation: An update of Empirical Findings," Research Policy, (26) 773-776, 1998.
} 
of Gellman, who studied innovations from 1953 to 1973 , with an average lag time of 7.2 years. ${ }^{18}$ Moreover, Mansfield reported a range of lag time from 4.2 years (instrument sector) to 9.8 years (metals) and that industry believed substantial delays of 9 years (or more) would have occurred in technology introduction without academic research in which such research played a significant role in technology development. However, to accurately account for the cost and benefits of public R\&D investment, the incubation time from the onset of R\&D to technology introduction should be between the first public-supported research finding in the area that leads significantly toward the product and the time of the private-sector commercial introduction, rather than between the most recently published research finding and commercial introduction. Such a modification would change the point of departure from the final engineering of the technology to the initial invention of the enabling science and technology.

In addition to the work of Mansfield and Gellman, analysis of 30 product-development and market sales cycles over 150 years was performed by Agarwal and Bayus, ${ }^{19}$ in which they conclude that average time from invention to "sales takeoff" (accelerating market penetration) is more than 42 years. That is, the length of time from invention to measurable market penetration - without accounting for any fundamental R\&D that preceded the specific product invention - is 42 years, across a broad range of consumer products. They based their estimate of the year of invention on several published sources ${ }^{20}$ and analyses; ${ }^{21}$ which, in general, defined invention as the year of the most recent patent, not the first patent or publication of fundamental technology. Their analysis is summarized in Figure 2.

\section{Descriptive Statistics for the Market Evolution of Product Innovations}

(Means)

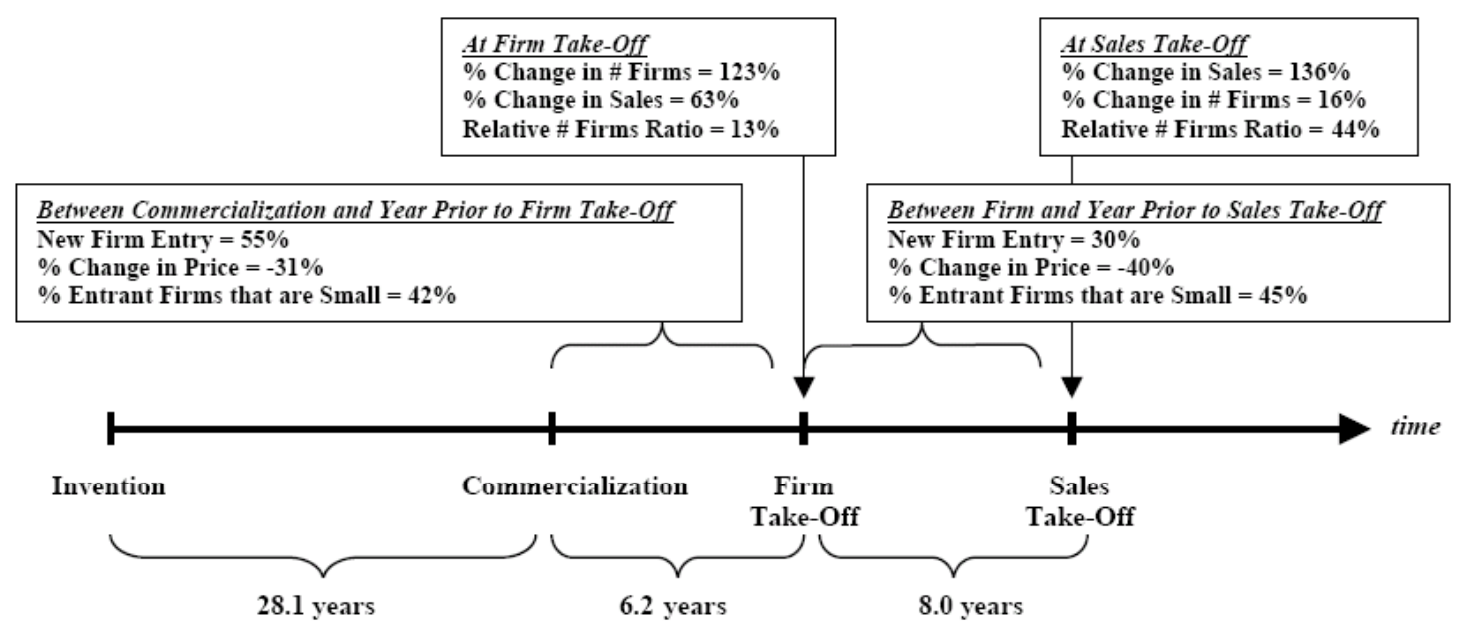

Figure 2. Descriptive statistics for market evolution of product innovations derived from analysis of 20 products by Agarwal and Bayus.

\footnotetext{
${ }^{18}$ Gellman Associates “Indicators of International Trends in Technology Innovation” report to the National Science Foundation, 1976.

${ }^{19}$ R. Agarwal and B. Bayus; "The Market Evolution and Sales Take-Off of Product Innovations," University of Illinois at Urbana working paper, 2002.

${ }^{20}$ V. Giscard d'Estaing; The Second World Almanac Book of Inventions, New York; Pharos Books, 1986.

${ }^{21}$ R. Kohli, D. Lehmann, and J. Pae; "Extend and Impact of Incubation Time in New Product Diffusion," J. Product Innovation Mgmt, 16(2), 123-144; 1999 and references therein.
} 
The further measure of the gestation time for fundamental $R \& D$ is also significant relative to any measure of advancement of technology into the market by public R\&D of fundamental technology. Several metrics exist to measure the effectiveness of $R \& D$ as a function of timefrom-research, including citation trees and patent citation temporal studies, but do not quantify impact on temporal change of product introduction. In the energy field, previous studies indicate that the research-market pipeline may be particularly long compared to other sectors. ${ }^{22,23}$

The research of Agarwal and Bayus also suggests that the number of firms commercializing a technology impacts the time to sales takeoff. They postulate that sales takeoff is caused by outward shifting supply and demand curves; and that firm entry not only affects supply - but also demand - for the product because product improvements, expanded distribution, and increased customer awareness result from increased marketing activities.

The fact that the time between invention and commercialization can be of great length demonstrates that implementation of the NRC 5-year rule can be problematic. In cases where commercialization has yet to occur - as in multiple cases in the NRC study - economic benefits are not counted or estimated although substantial future benefits may or are expected to occur. ${ }^{24}$

\section{Diffusion time for technology market penetration and implications for measurement of economic benefits of public $R \& D$}

Product introduction into the market has been examined in depth. The fundamental diffusion model as introduced by Bass in 1969 includes two primary factors that characterize the market penetration of a given invention: innovation and imitation. ${ }^{9}$ The innovation coefficient, $p$, characterizes the rate of early adoption; and imitation coefficient, q, characterizes the rate of majority adaptation. Analysis by Sultan, Farley, and Lehmann for more than 200 product innovations indicates average values of 0.03 for $p$ and 0.38 for $\mathrm{q}^{25}$ However, more significantly, the standard deviation of $p$ and $q$ are 0.03 and 0.35 . That is, use of average values for any specific technology is not statistically justified. The variance in the values of $p$ and $q$, in effect, indicates that product diffusion occurs as short as a few years for products like cellular telephones, and longer then 50 years for compact fluorescent lightbulbs; and that utilization of a single value for multiple technologies or in different industry sectors will lead to misleading results.

In Figure 3, market-penetration curves are derived for the minimum, average, and maximum values of $\mathrm{p}$ and $\mathrm{q}$ using the Bass model. Time to maximum market penetration varies from seven years for minimum values of $\mathrm{p}$ and $\mathrm{q}$ to more than 300 years for maximum values of $\mathrm{p}$ and $\mathrm{q}$, as reported by Sultan, Farley, and Lehmann.

\footnotetext{
${ }^{22}$ R. Margolis and D.M. Kammen, "Energy R\&D and Innovation: Challenges and Opportunities" in Schneider, S.A Rosencranz, and J. Nices, editors, A Reader in Climate Change Policy, Island Press, Washington D.C., 2001.

${ }^{23}$ R. Margolis and D.M. Kammen, "Underinvestment: the energy technology and R\&D policy challenge", Science, 285, 690-692, 1999.

${ }^{24}$ For example, case studies on compact fluorescent lamps, black liquor gasification, IOF Forest Program, PNGV, and fuel cells as detailed in Reference 9.

${ }^{25}$ F. Sultan, J.U. Farley and D.R. Lehmann; “A Meta-Analysis of Applications of Diffusion Models,” J. Marketing Res. 27: 70-77, 1990.
} 
Variance of Market-Penetration Time

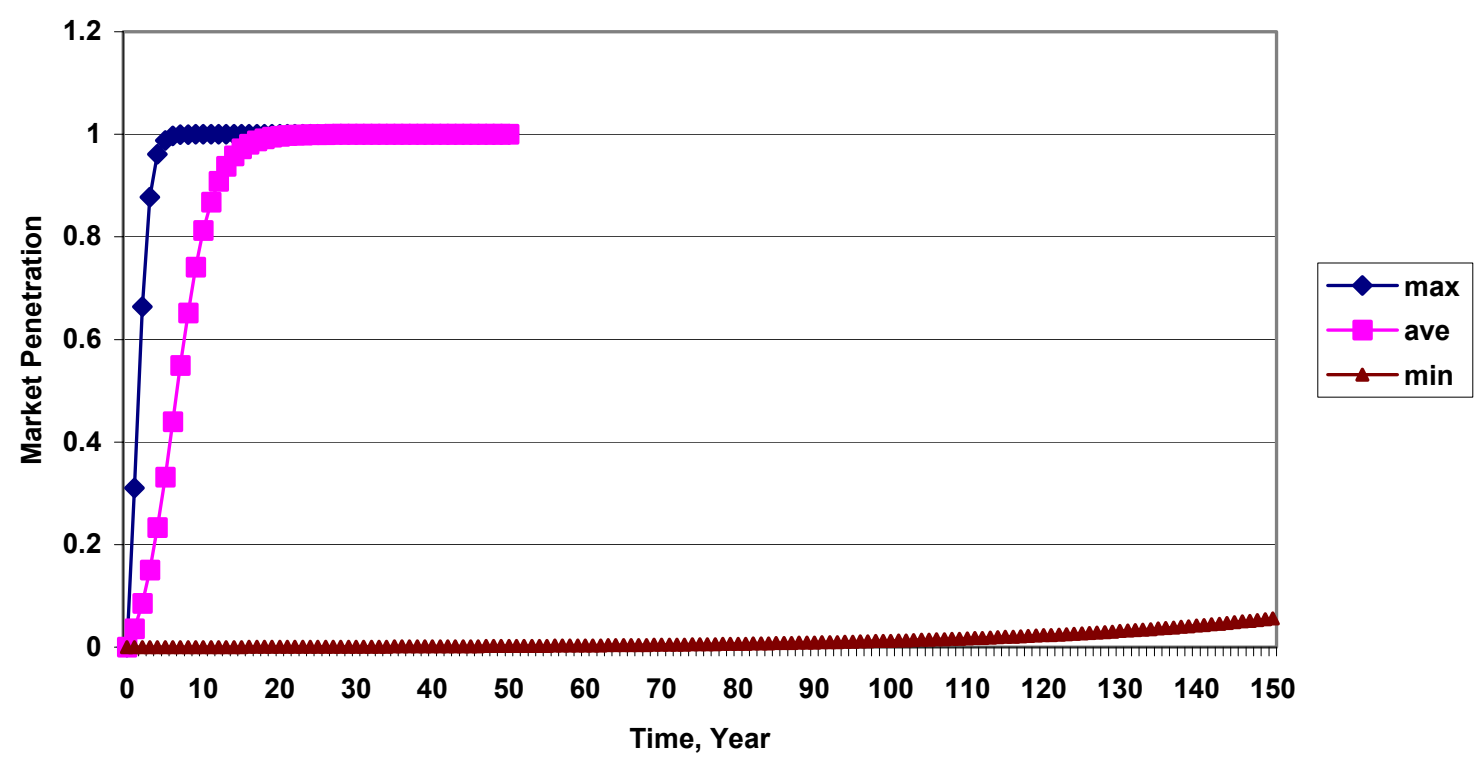

Figure 3. Market-penetration curves based on Bass Diffusion model and utilizing minimum, average, and maximum values for $p$ and $q$ as reported by Sultan, Farley, and Lehmann. Corresponding time to maximum market penetration are 7 years, 17 years, and more than 300 years.

Examples of the heterogeneity of market-penetration rates for a sample of energy-sector technologies are summarized by Elliot et al. ${ }^{26}$ As shown in Figure 4, the range of times to $90 \%$ of maximum market penetration for the reported technologies is from 10 years to more than 50 years. As detailed above, the results by Sultan et al indicate a range of penetration times (measured to $90 \%$ of maximum market penetration) from 7 years to more than 350 years, with an average of 17 years.

The market structure may also impact technology penetration rates (e.g., monopoly structures could be argued to either accelerate or retard penetration rates compared to oligopolies or commercial markets). The technologies reported by Elliot et al represent a mix of market structures and do not necessarily compare with the breadth of product/market combinations reported in other studies. Moreover, specific independent analysis of the impact of market structure on penetration rates has not been previously codified for the energy sector.

Nonetheless, the results available to date suggest that fundamental technology (funded by the public sector) penetration in the energy sector most likely occurs on a longer time scale than that stipulated by the NRC "2005 rule"; and, accordingly, accrual of net economic benefits should be based on units sold over a longer period of time from the date of the study.

\footnotetext{
${ }^{26}$ D.B. Elliott et al; "Methodological Framework for Analysis of Buildings-Related Programs: The GPRA Metrics Effort,” PNNL Report 14697, 2004.
} 


\section{Normalized Penetration}

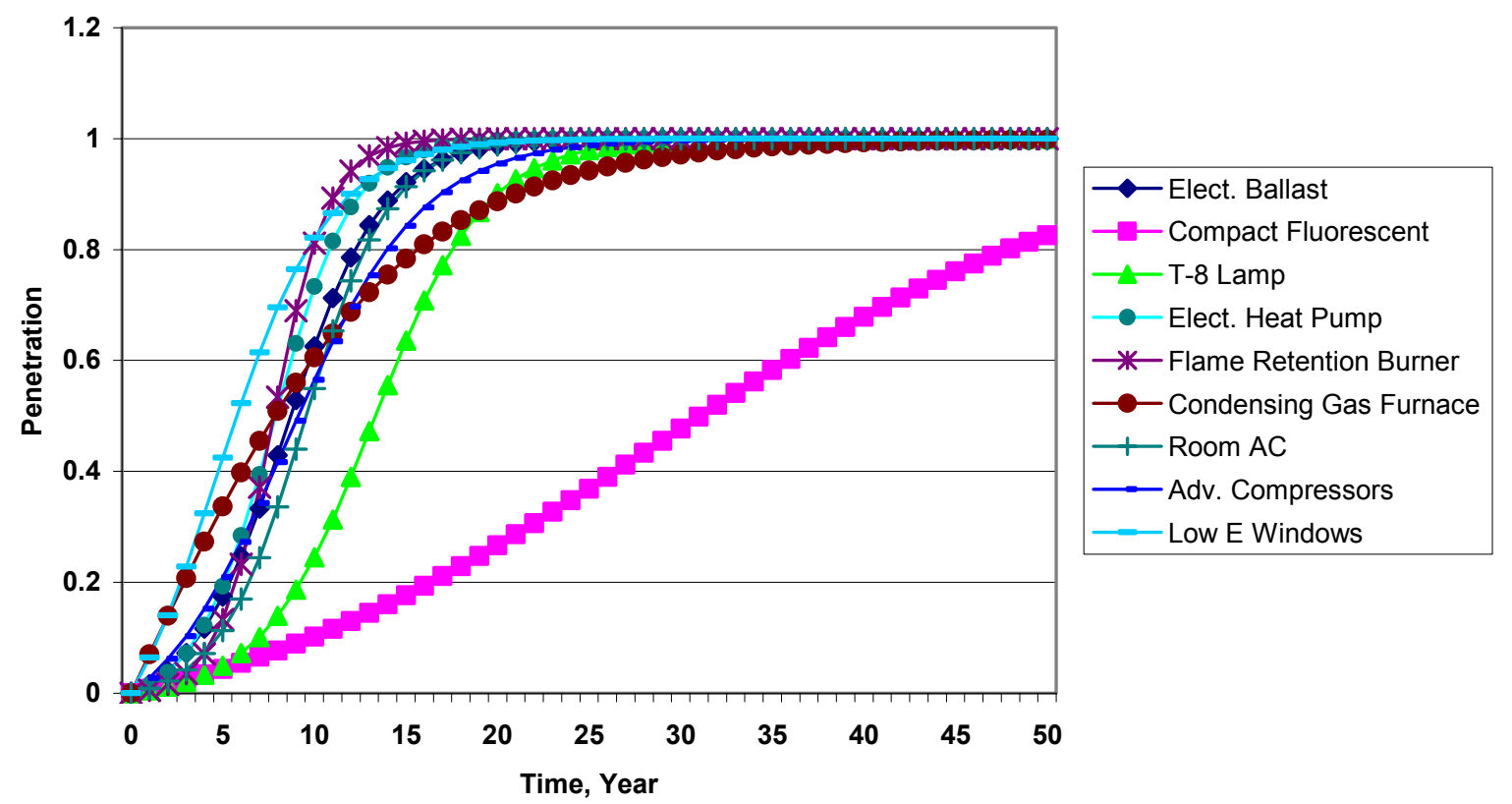

Figure 4. Normalized market penetration curves derived from Bass Diffusion modeling for a sample of energy-sector technologies. Diffusion parameters are summarized by Elliot et al. ${ }^{22}$

Further, evaluation of diffusion rates in sectors that have long-lived infrastructure, and for fundamental changes in technology use in various sectors, has been published by Grubler. ${ }^{7}$ Analysis of more than 265 diffusion processes in the United States indicated a mean value for time to market penetration from $10 \%$ to $90 \%(\Delta \mathrm{t})$ of 41 years. Half of the diffusion processes had $\Delta \mathrm{t}$ of fewer than 30 years, and $7 \%$ of the processes had $\Delta \mathrm{t}$ of more than 100 years. As an example, Figure 5 shows the shares of total primary energy in the United States supplied by different fuels (top panel) and estimates for the consumption of major primary fuels worldwide (bottom panel). Here, major changes in energy fuel supply occur on the order of a century. Fundamental inventions would accordingly accrue net benefits through the technology cycle that is on the order of 100 years. According to Grubler:

As with the evolution of particular technologies and infrastructures, the diffusion of energy sources follows a similar pattern. The market share of a fuel expands initially slowly as gradually expanding niche markets are filled; a more lengthy process of pervasive diffusion follows, eventually saturating and declining as a superior competitor enters and diffuses. Despite the simultaneous competition and interaction among many different sources of energy, each historical period is characterized by a clear dominance of a single energy source, which corresponds with the main technological clusters: fuelwood (and feed), followed by coal, and later by oil and natural gas. The rates for diffusion also correspond: all of the major fuels (wood, coal, oil, gas) required a century to achieve their ultimate saturation. The time constant for nuclear is not yet evident because it has low market share. 

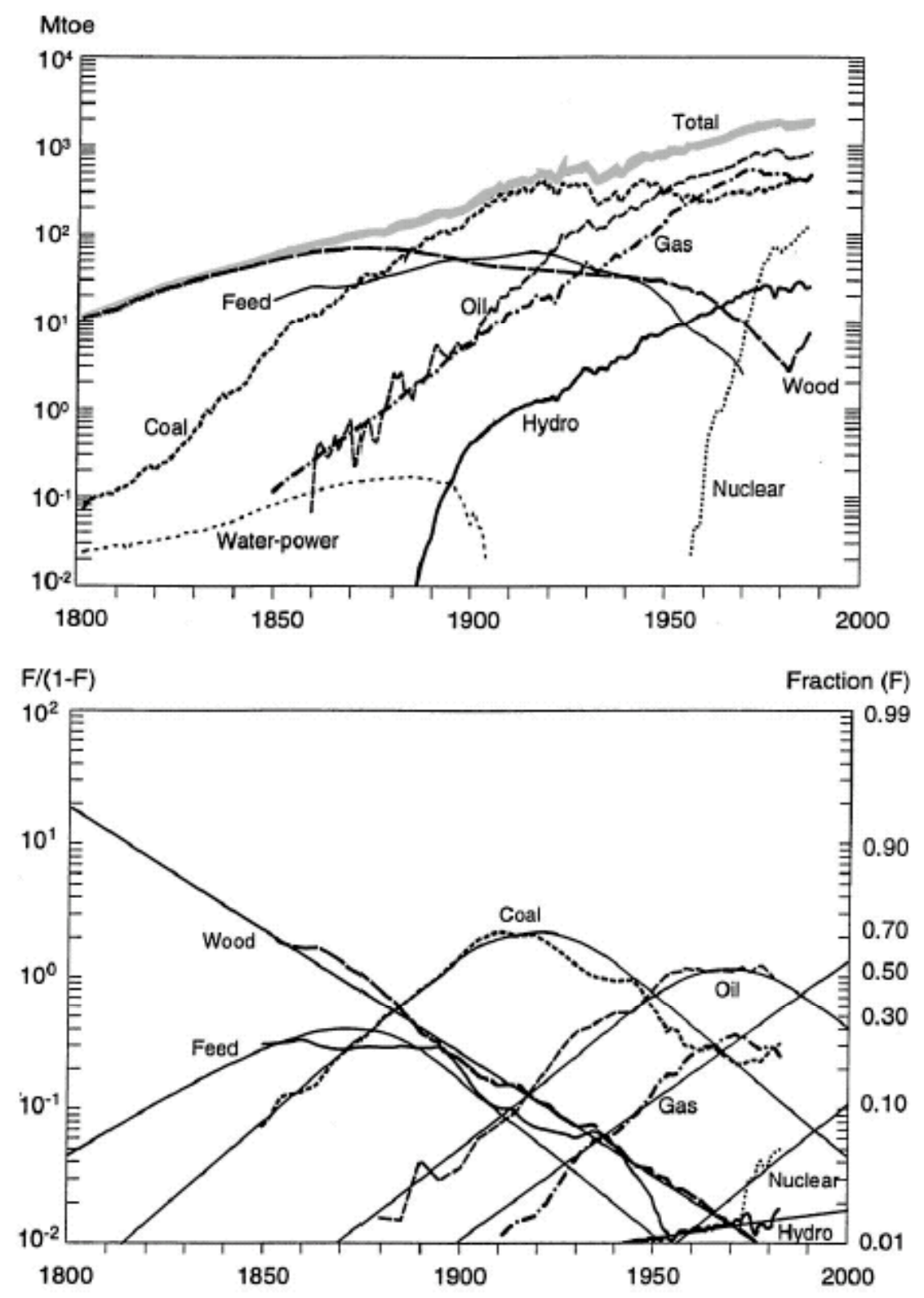

Figure 5. Selection of energy source supply in the United States from 1800 to 2000. The top figure reports in million tons of oil equivalent (Mtoe) and the bottom reports in fraction of market served (penetration). From Grubler. ${ }^{7}$

From analysis of historical data, Grubler drew the following conclusion: "It is impossible to determine - from theory or statistical analysis of historical data - exactly what rates $(\Delta \mathrm{ts})$ will prevail in particular circumstances". ${ }^{7}$ This, more significantly, does not take into account R\&D and product-development time. The findings of Agarwal and Bayus and Grubler report on sequential time periods for product invention, commercialization, and penetration, respectfully, and thus may be added to provide an assessment of time from invention to mature market penetration. Using average values from the literature - excluding preceding R\&D - the time from invention to market penetration of $90 \%$ is about 80 years, with a range as low as 20 years and as high as two centuries for long-lived infrastructure technologies. 
The peer-reviewed literature supports the conclusion that technology cycles vary widely, and the time for complete market penetration of a given technology may be a few years to decades depending on market barriers and stock turnover. Consequently, the peer-reviewed literature supports the conclusion that use of a simplified method or uniform time frame that limits the measurement of prospective economic benefits to a given technology to five years would lead to erroneous results.

\section{Implications and Case Examples}

Any rule rigidly applied to new and innovative technologies may miss fundamental interrelationships involved in the market entry. The NRC simplifying "rules," as specified in their 2001 report, likely will result in estimated net economic benefits that are less than their actual values.

One of NRC's own case studies illustrates how government R\&D also may be necessary to address technology barriers in areas where industry efforts failed to produce the critical outputs and also shows the difficulty of the use of the simplifying rules. For example, lost-foam technology is used in metal casting as an alternative to sand casting. As noted by the NRC committee, the lost-foam technology was invented by the private sector in the 1950s. And industry, including large manufacturers such as General Motors, tried to solve the technical problems and failed. DOE funded R\&D on lost-foam technology from 1989 through 2001 as part of an industry consortium in which DOE matched industry funding one-to-one. By the mid1990s, technical problems had been solved and the technology quickly began market penetration. Significant energy savings have been realized and DOE received strong support from the consortia members. However, it is unclear how the simplifying rules could be applied in this case and lead to meaningful results.

\section{Impact of advancement of market penetration and time to market maturity}

In a recent unpublished paper at NREL, Norland ${ }^{27}$ uses an analysis of a hypothetical technology and the impacts of applying the NRC "rules" under different conditions including (a) the number of years the technology is advanced in its market penetration by public investment, compared to the counterfactual case of only private-sector investment, and (b) the number of years it takes the technology to reach its maximum market share for annual sales.

The analysis uses the following assumptions:

- The technology has a useful life of 30 years.

- The technology entered the market in 1990.

- The technology takes $20,30,40$, or 50 years to reach maximum annual sales.

- The year of analysis is 2005; the last year of including units sold in estimating net economic benefits using the NRC rules is 2010 .

- The impact of the government R\&D program is to shift the number of units sold forward in time.

- The acceleration of product introduction by government R\&D is $5,10,15$, or 20 years.

${ }^{27}$ D. Norland, forthcoming. 
Norland's conditions are consistent with the NRC committee assumption that per unit sales were the same for the cases of public and five-year-later private sales. This assumption implies that market penetration rates may be different if the underlying market is changing. Figure $\mathbf{6}$ shows the relative net economic benefit compared to the case defined by the NRC rules as a function of years of advancement for a number of data sets representing different time to maximum market penetration. For example, for a technology with maximum sales penetration in 20 years - where public-sector R\&D advanced the technology into the market five years earlier than the case of only private-sector funding - the application of the NRC rules results in underestimation of the net economic benefits by $15 \%$.

Impact of R\&D Acceleration

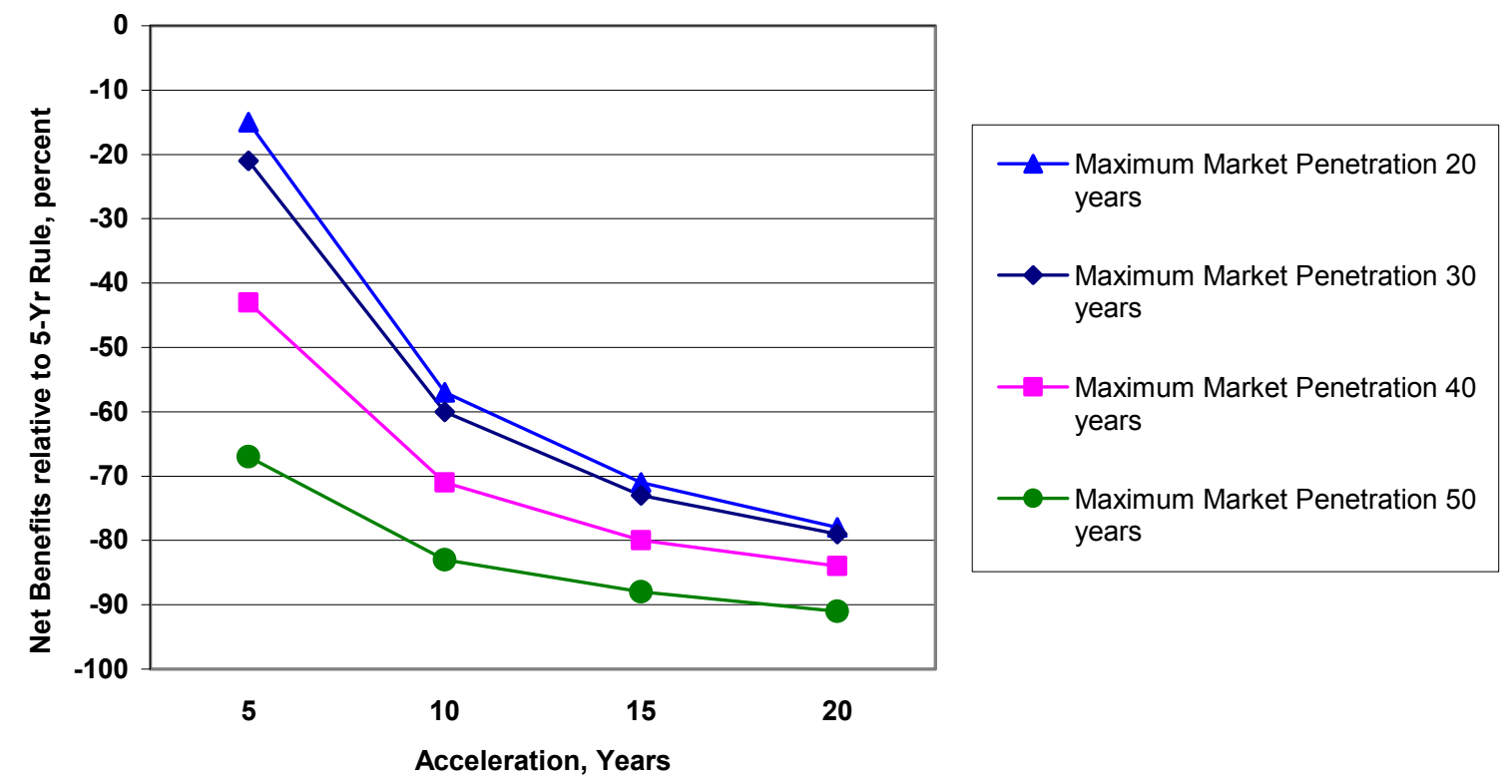

Figure 6. Net economic benefit relative to the case utilizing the NRC rules for different advancement of product introduction into the market by public-sector R\&D, shown for technologies with maximum market penetration of $20,30,40$, and 50 years. Other assumptions are stated above.

As the advancement of the technology into the market increases, the application of the NRC rules would underestimate the net economic benefits by greater amounts: $58 \%$ underestimation in the case of 10 years advancement and $78 \%$ in the case of 20 years advancement (this applies to a technology with a time to maximum sales of 20 years and the assumptions stated above).

The impact of the application of the NRC rules as a function of the time for maximum market sales is shown for values of maximum sales of 20, 30, 40 and 50 years (representing the 20 years faster market penetration than found by Grubler, on average, and 10 years longer). Here, the application of the NRC rules, assuming the NRC 5-year advancement rule, results in underestimation of the net economic benefits of $15 \%$ to $67 \%$ for time to maximum sales of 20 years and 50 years, respectively. For all cases, the application of the NRC rules underestimates potential benefits, ranging from $15 \%$ to $91 \%$ depending on the specific case. 


\section{Impact of time frame for estimation of economic benefits}

The NRC committee assumed that net benefits are associated with units sold up to five years from the date of the study, the "5-year rule". Peer-reviewed literature and specific case studies of energy technologies indicate that technology penetration may take many decades. As illustrated by the lost-foam case, it is unreasonable to assume the private sector will develop and successfully introduce alternative technology into the marketplace in the absence of public R\&D. Further, Tassey has argued that measurement of net economic benefits of a fundamental technology accrue throughout the complete technology life cycle. ${ }^{8}$ To illustrate the impact of the application of the "5-year rule," we calculate the impact of changing the eligible time for estimating net economic benefits based on units sold from five years to 15 years. Using average market-penetration values for the Bass Model—and assuming early market penetration, similar net economic impact per-unit sales, and no discounting-increasing the time that units sold contribute to the estimation of net economic benefits from five years to 15 years results in an increase in net economic benefits of $293 \%$. Accuracy of the estimation of net economic benefits is strongly dependent on the time allowed for contributions to be included, as well as the useful life of those units, and must include accurately determining the start time (year) of the study. For example, the lost-foam case illustrates where defining the start date in the 1950s would lead to significantly different results compared to defining the start date in 1989, the initial year of DOE funding. Agreement on a standard definition for the start time, as well as the availability of reliable data, are necessary for performing and comparing net economic benefit estimates.

\section{Conclusions and Recommendations}

Our review of the literature does not point to one rule or set of criteria that can be applied uniformly in estimating net economic benefits. Research suggests that the uniform application of a set of rules may lead to erroneous results as well as interpretation by analysts, program managers, and policy makers. The use of simplifying rules such as those employed by the NRC committee would be inappropriate for R\&D portfolio planning; where other methodologies such as scenario planning, decision-tree analysis, and real options allow for improved assessment of net economic benefits from R\&D investments. Using literature data (on average) excluding preceding $R \& D$, the time from invention to market penetration of $90 \%$ is about 80 years, with a range as low as 20 years and as high as two centuries for long-lived infrastructure technologies; and, thus, this data indicates any arbitrary cutoff to the evaluation interval would severely underestimate benefits and undervalue investment. Finally, while there is reasonable evidence in the literature that public R\&D provides significant social return on investment, there is still no consensus on the impact of public R\&D on the advancement of a technology into the market, the time required for a technology to penetrate the market to a certain point, discount rates for public benefits, or methods for quantification of public goods.

From an econometric perspective, considerations for the development of an alternative approach call for the use of valid data through a complete R\&D and technology cycle. This may range from years to decades depending on stock turnover. Valid projections of market penetration may be obtained by statistical analysis of early market data using advanced modeling techniques. Statistically validated data for similar technologies in the same industry sector may offer valid insights into acceptable market acceleration. 
Considerations for revised methodologies include use of independently verified case-specific information for (i) the initial year of analysis (ii) the time of advancement of a technology into the market by public $R \& D$ and (iii) the time for accrual of benefits based on the use of technology-specific data when available. In the absence of technology-specific data, the use of sector data may be a reasonable proxy, including advanced forecasting techniques for technologies in the early stages of market penetration. ${ }^{28,29}$

Further, while not reviewed in detail in this paper, best practices economic modeling suggests that revised methodologies should use appropriate discount rates, employ scenario analysis, and apply options analysis to assess potential risk and uncertainty impacts. ${ }^{30}$ Finally, estimation models should incorporate the use of sensitivity analysis to evaluate the robustness of the approach and model.

\footnotetext{
${ }^{28}$ See, for example, S.R. Dala, Y-Y Ho and R. P. Sherman; "Learning From Experience To Improve Early Forecasts: A Posterior Mode Approach," Business \& Economics for the $21^{\text {st }}$ Century - Volume II, Business and Economics Society International, 1998.

${ }^{29}$ T. Garber, J. Goldenberg, B. Libai, and E. Muller; "From Density to Destiny: Use of Spatial Analysis for Early Prediction of New Product Success," Marketing Science, 2004.

${ }^{30}$ Scenario analysis allows one to capture the probability distribution of nondeterministic variables. The use of Monte Carlo techniques allows for the evaluation of multivariable analysis and provides probabilistic bounds to estimates of net economic benefits. Real Options theory accounts for uncertainty of the outcome and irreversibility of committed resources and is argued to more completely capture the full value of an investment opportunity (see Ref. 2).
} 


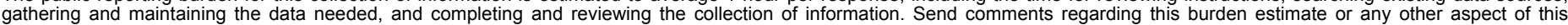

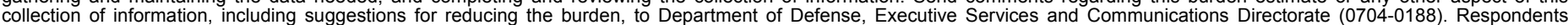

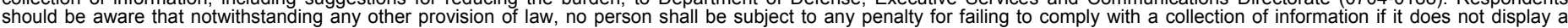

should be aware that notwithstanding

PLEASE DO NOT RETURN YOUR FORM TO THE ABOVE ORGANIZATION.

\begin{tabular}{|c|c|c|}
\hline $\begin{array}{l}\text { 1. REPORT DATE (DD-MM-YYYY) } \\
\text { January } 2005\end{array}$ & 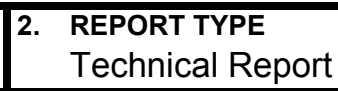 & 3. DATES COVERED (From - To, \\
\hline
\end{tabular}

4. TITLE AND SUBTITLE

R\&D Advancement, Technology Diffusion, and Impact on Evaluation

DE-AC36-99-G010337

of Public R\&D

5b. GRANT NUMBER

5c. PROGRAM ELEMENT NUMBER

6. AUTHOR(S)

M.C. Moore, D.J. Arent, and D. Norland

5d. PROJECT NUMBER

NREL/TP-620-37102

5e. TASK NUMBER

ASA4.4047

5f. WORK UNIT NUMBER

7. PERFORMING ORGANIZATION NAME(S) AND ADDRESS(ES)

National Renewable Energy Laboratory

1617 Cole Blvd.

8. PERFORMING ORGANIZATION

REPORT NUMBER

Golden, CO 80401-3393

NREL/TP-620-37102

9. SPONSORING/MONITORING AGENCY NAME(S) AND ADDRESS(ES)

10. SPONSOR/MONITOR'S ACRONYM(S)

NREL

11. SPONSORING/MONITORING AGENCY REPORT NUMBER

12. DISTRIBUTION AVAILABILITY STATEMENT

National Technical Information Service

U.S. Department of Commerce

5285 Port Royal Road

Springfield, VA 22161

\section{SUPPLEMENTARY NOTES}

\section{ABSTRACT (Maximum 200 Words)}

In a 2001 report titled "Research at DOE: Was It Worth It?" a National Research Council (NRC) committee defined a set of simplifying rules to estimate the net economic benefits from technologies supported by the Department of Energy (DOE). This paper evaluates the efficacy of the NRC rules compared to published literature on acceleration of technology introduction into markets, technology diffusion, and infrastructure change. It also offers considerations for revisions of the rules that call for the use of technology and sector-specific data, advanced forecasting techniques, and sensitivity analysis to test the robustness of the methodology.

\section{SUBJECT TERMS}

National Research Council; R\&D investments; net present value; return on investment; economic-benefits evaluation; discount rates; market evolution; market penetration; product innovations; scenario analysis; options analysis; Michal C. Moore; Douglas J. Arent; Douglas Norland

\begin{tabular}{|c|c|c|c|c|}
\hline \multicolumn{3}{|c|}{ 16. SECURITY CLASSIFICATION OF: } & \multirow{2}{*}{$\begin{array}{l}\text { 17. LIMITATION } \\
\text { OF ABSTRACT } \\
\text { UL }\end{array}$} & \multirow{2}{*}{$\begin{array}{ll}\text { 18. } & \text { NUMBER } \\
\text { OF PAGES }\end{array}$} \\
\hline $\begin{array}{l}\text { a. REPORT } \\
\text { Unclassified }\end{array}$ & $\begin{array}{l}\text { b. ABSTRACT } \\
\text { Unclassified }\end{array}$ & $\begin{array}{l}\text { c. THIS PAGE } \\
\text { Unclassified }\end{array}$ & & \\
\hline
\end{tabular}

19a. NAME OF RESPONSIBLE PERSON

19b. TELEPHONE NUMBER (Include area code) 